\title{
Anaesthesia and allergic drug reactions
}

\author{
G. C. Moudgil MB M SC FFARCS FRCPC
}

An allergic drug reaction, by definition, is an untoward physiologic response produced by an immunologically mediated reaction. Although a wide variety of factors such as physico-chemical interaction, enzyme induction or inhibition, drug overdose or toxicity, may all contribute toward adverse drug reactions, these should be distinguished from immunologically mediated allergic drug reactions that occur capriciously and explosively, with little or no warning. Contrary to the common belief, allergic reactions are not rare. In the United States of America, approximately 200,000 patients suffer an allergic drug reaction each year during their stay in the hospital. Another one million people probably experience milder reactions that do not require hospital treatment. ${ }^{1}$ It has been estimated that one of every six patients requiring medical treatment has suffered a true or suspected allergic reaction to a drug at some time. The use of a greater number of drugs in the perioperative period has resulted in an enhanced incidence of allergic drug reactions during anaesthesia. ${ }^{2}$ Since allergic drug reactions are potentially life threatening, their prompt recognition and treatment are essential for the patient's survival and well being. Therefore, an understanding of the pathogenesis, clinical manifestation, diagnosis, treatment and prevention of allergic drug reactions is essential for better patient care and management.

\section{Pathogenesis of allergic drug reactions}

The ability of the body to recognize and respond to the "non self" forms the basis of the immune response. Following exposure to a foreign substance (an antigen), the body may either develop specific serum protein molecules called antibodies, or produce immunologically sensitized lymphocytes. The production of antibodies and the subsequent antigen-antibody reaction forms the basis of humoral immunity, whereas the induction of sensitized lymphocytes is called cellular immunity.
Compounds of low molecular weight (500-1000) are incapable of eliciting antibody formation, and as such are incomplete antigens or haptens.

Most drugs, their metabolites, and preservatives such as methyl paraben are incomplete antigens. Only after conjugation with a protein called a "carrier" do they become allergenic or immunogenic. ${ }^{3}$ For this to occur a stable covalent bond is essential. ${ }^{4}$ The commonly observed pharmacologic binding of drugs to the serum proteins is too weak to render them immunogenic. Immunogenicity may be accomplished when a drug contains a chemically reactive group such as an anhydride or a quinone. Altematively, a spontaneous or enzymatic conversion of the drug in the body may also create chemically reactive groups that are likely to render it immunogenic.

Exposure to such drugs or chemically similar substances results in the production of antibodies such as immunoglobulin $\mathrm{E}$ (IgE), immunoglobulin G (IgG), and immunoglobulin M (IgM), by the plasma cells. Subsequent exposures to these drugs may cause an antigen-antibody reaction which releases pharmacologically active mediators responsible for the ultimate adverse effects. Previous uneventful single or repeated exposures to the same or similar drugs do not negate the possibility of a severe allergic response on subsequent exposures. ${ }^{5}$

In addition to immune system mediated allergic reactions, where a previous exposure to the drug is mandatory, drug reactions may also occur by a direct effect of the drugs on the effector cells. These non-immunologic drug reactions have been classed as anaphylactoid reactions and their clinical manifestations are indistinguishable from the immune mediated allergic reactions.

From the Department of Anaesthesia, McMaster University Medical Centre, 1200 Main Street West, Hamilton, Ontario, L8N 3 Z5. 


\section{Classification of allergic reactions}

Allergic drug reactions may be subdivided into immune system mediated "anaphylactic reactions" and non-immune direct responses called "anaphylactoid reactions."

\section{Immune system mediated drug reactions}

More than twenty years ago Gell and Coombs described the following four basic types of allergic reactions that are mediated by immune processes. 6

TYPE I - ANAPHYLACTIC OR IMMEDIATE HYPERSENSITIVITY

A previous exposure to the same, or a similar pharmacologic agent is necessary for this type of reaction to occur. The earlier exposure to the pharmacologic agent results in the production of antibody of the IgE immunoglobin class. The principal site of IgE synthesis is in the lymphatic tissue of the respiratory and gastrointestinal systems, with tonsils and adenoids being particularly rich in IgE forming plasma cells. The IgE antibody because of its specific affinity, binds on to the surface receptors of basophils and mast cells. The $\mathrm{IgE}$ receptor is a glycoprotein with molecular weight of approximately $50,000 .^{7}$ The receptor is an integral component of the cell membrane of basophils and mast cells and is not seen on any other types of leucocytes. ${ }^{8}$ It has been estimated that between 40,000 and $100,000 \mathrm{IgE}$ receptors are present on human basophils. The binding of IgE with its receptor is temperature dependent, quite specific, and not affected by immunoglobulins of other classes. ${ }^{9}$ Once the antibodies have been bound to mast cells and basophils, these cells are ready to participate in the immediate hypersensitivity reaction upon appropriate antigenic stimulation. Such an allergenic stimulus is provided by a re-exposure to the same or similar drug. The drug forms a bridge across the two cell-bound $\operatorname{lgE}$ antibody molecules and cross-links them. The cross-linking induces a membrane change which results in an influx of calcium ions and changes in cyclic nucleotide levels. A fall in cyclic $3^{\prime}, 5^{\prime}$ adenosine monophosphate (cAMP) or a rise in cyclic $3^{\prime}, 5^{\prime}$-guanosine monophosphate (cGMP) favours mast cell degranulation and mediator release, whereas high concentrations of cAMP stabilize the mast cell granules.

The extent of cellular degranulation is influenced by the dose and the affinity of the drug for the $\operatorname{lgE}$ antibodies, the number of cell-bound $\mathrm{IgE}$ antibodies and the intracellular concentration of cyclic nucleotides. ${ }^{10}$ Degranulation and the subsequent release of chemical mediators is an energy dependent process which results in a substantial fall of the intracellular ATP levels. The clinical expressions of type I hypersensitivity include anaphylaxis, extrinsic asthma and extrinsic rhinitis.

\section{TYPE 1 I - CYTOTOXIC HYPERSENSITIVITY}

This reaction is caused by an IgG or IgM antibody that is directed at the cell surface antigen. The antigens may be an integral part of the cell membrane, e.g., A or B blood group antigens or they may be surface adsorbed haptens which stimulate an antihapten antibody production. Following antigen-antibody interaction, contact with phagocytes is enhanced by a reduction in surface charge, and by opsonic or immune adherence through the membrane bound complement protein $\mathrm{C}_{3}$. As a result of this increased cell adherence, cell death is enhanced by phagocytosis. Cell damage may also result following the complete activation of the complement system. The classical complement system consists of nine separate components numbered $\mathrm{C}_{1}$ to $\mathrm{C}_{9}$, that on activation interact sequentially with one another in a cascade fashion (Figure). The

\begin{tabular}{|c|c|c|c|}
\hline$C_{1}$ & $\stackrel{\mathrm{Ab}-\mathrm{Ag}}{\longrightarrow}$ & \multicolumn{2}{|l|}{$C_{\bar{T}}$} \\
\hline$C_{4}+C_{2}$ & $\underline{\mathrm{C}_{1}^{-}}$ & \multicolumn{2}{|c|}{$\begin{array}{r}\mathrm{C}_{\overline{42}}+\text { Fragments with } \\
\text { kinin-like activity }\end{array}$} \\
\hline$C_{3}$ & $\stackrel{\mathrm{C}_{\overline{1,4,2},}}{\longrightarrow}$ & $\begin{array}{l}\mathrm{C}_{3 b} \\
\text { Enhanced } \\
\text { phagocytosis }\end{array}$ & $\begin{array}{l}+\mathbf{C}_{3_{a}} \\
\text { Anaphylatoxin } \\
\text { Chemotactic }\end{array}$ \\
\hline$C_{5}$ & $\stackrel{C_{1,4,2,3}}{\longrightarrow}$ & \multicolumn{2}{|l|}{$\begin{array}{l}\mathrm{C}_{5 \mathrm{~b}}+\mathrm{C}_{5 \mathrm{a}} \\
\text { Anaphylatoxin } \\
\text { Chemotactic }\end{array}$} \\
\hline $\mathrm{C}_{6}+\mathrm{C}_{7}$ & $\underline{C_{s b}}$ & \multicolumn{2}{|l|}{$\begin{array}{l}C_{5,6.7} \\
\text { Chemotactic }\end{array}$} \\
\hline$C_{g}+C_{9}$ & $\mathrm{C}_{5,6.7}$ & \multicolumn{2}{|l|}{$\begin{array}{l}\mathrm{C}_{5,6,7,8,9} \\
\text { Cytolysis }\end{array}$} \\
\hline $\begin{array}{l}\mathrm{C}_{1}-\mathrm{C}_{9}=\mathrm{C} \\
\mathrm{Ab}-\mathrm{Ag}= \\
\text { Bars aboy }\end{array}$ & $\begin{array}{l}\text { onents of } \\
\text { ody-anti }\end{array}$ & $\begin{array}{l}\text { plement system. } \\
\text { omplex. }\end{array}$ & 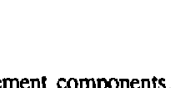 \\
\hline
\end{tabular}

FIGURE Flow diagram of complement cascade 
complement system, once activated is probably the most important source of vasoactive mediators. For example, activated complement proteins $\mathrm{C}_{3 \mathrm{a}}$ and $\mathrm{C}_{5 \mathrm{a}}$ are potent anaphylatoxins and leucocyte chemoattractants. "The anaphylatoxins $\mathrm{C}_{3 \mathrm{a}}$ and $\mathrm{C}_{5 \mathrm{a}}$ release histamine and other vasoactive substances from mast cells which produce arteriolar dilatation and increased vascular permeability. The actual damage in Type II reactions results from cell lysis either by phagocytosis or through complement system activation. The most common examples of Type II reactions in man are transfusion reactions and penicillin induced haemolytic anaemia.

TYPE III - IMMUNE COMPLEX-MEDIATED REACTIONS Type III allergic reactions are also IgG and IgM mediated reactions and can be subdivided into local (Arthus) or generalized (serum sickness) reactions. These reactions involve soluble rather than particulate antigens. The formation of antigen-antibody complexes cause an activation of complement system with subsequent neutrophil chemotaxis and proteolytic enzyme liberations. Also there is platelet aggregation and microthrombi formation with ischaemia, which provide yet a further source of vasoactive amine liberation and subsequent tissue damage. Presence of large amounts of circulating complexes ultimately leads to their deposition in the basement membranes and blood vessels of the skin, kidneys, and the central nervous system. When the circulating antibody levels are high, the antigen gets precipitated near the site of entry into the body. The reaction in the skin is characterized by polymorph infiltration, oedema and erythema and forms the essentials of the Arthus reaction. In contrast, when there is an antigen excess soluble complexes are formed and deposited in the kidney glomerulii, the joints, skin and the choroid plexus. Complement is subsequently fixed and produces cellular damage. Well known examples of type III generalized or systemic reactions include serum sickness and immune complex nephritis.

TYPE IV - DELAYED HYPERSENSITIVITY

Delayed hypersensitivity reactions occur without the involvement of antibodies or the complement system and are entirely cell-mediated responses. The reactions result from the interaction between specificially sensitized T-lymphocytes and the specific antigens. Delayed hypersensitivity has been observed in response to bacteria, viruses, and in rejection of transplanted tissues. However, a wide range of drugs, cosmetics, soaps and dyes, may cause dermal sensitivity by the mechanisms of delayed hypersensitivity. Initially the antigen is processed and presented by macrophages to a small number of T-lymphocytes which become sensitized to the antigen. On subsequent contact with antigen these lymphocytes undergo mitosis, proliferate and produce soluble mediators called lymphokines. There is also a generation of cytotoxic T-cells. Temporally the production of the lymphokines is the first step to occur and their liberation in vitro can be detected within four hours after the binding of the antigen to the previously sensitized T-cells. Lymphokines influence the functions of macrophages, polymorphonuclear leucocytes, lymphocytes and other cells. Some of the important lymphokine mediated activities include the liberation of macrophage migration inhibition factor (MIF), macrophage activation factor (MAF), and monocytes and polymorphonuclear leucocytes chemotactic factors. It is the collective activity of these mediators which is responsible for delayed hypersensitivity. These reactions develop slowly, first appearing in 18-24 hours, reaching their peak at about 48 hours, and gradually disappearing by 72-96 hours. The examples of type IV reactions include graft vs. host reactions, the tuberculin reactions and contact dermatitis.

\section{Non-immune allergic reactions}

ANAPHYLACTOID REACTIONS

Clinical manifestations of drug induced, non-immune anaphylactoid reactions are indistinguishable from those of an immune-mediated anaphylactic drug reaction. However, in the anaphylactoid reactions the immune mediated mechanisms are either absent or their involvement cannot be proven. Since there is no immunologic-basis for anaphylactoid reactions, previous exposure to the drug is not necessary and the reaction may occur on the very first "virgin" exposure. Primarily basic drugs, e.g., d-tubocurarine, succinylcholinè, thiopentone, trimetaphan and polymyxin are capable of displacing directly another basic molecule such as histamine from mast cells and basophils and this forms the basis of directly mediated anaphylactoid drug reactions in susceptible persons. ${ }^{10}$ The susceptibility 
towards these reactions is enhanced by genetic features such as atopy, abnormalities of the complement system, and frequency of prior exposure to the drug. The severity of the adverse reaction is related to the dose and the speed of administration of the drug, since the severity of clinical adverse effects is directly related to the quantity of drug-induced release of histamine and other chemical mediators. ${ }^{12,13}$ Thus a rapid and high dose intravenous administration of a basic drug is likely to provoke a more prompt degranulation of mast cells and basophils and thereby influence the severity of an anaphylactoid reaction.

\section{Chemical mediators released in allergic reaction} Irrespective of the mechanisms of drug allergy, some chemical mediators are released during the allergic reactions. Although more than 20 different mediators have been identified, ${ }^{14}$ histamine remains the principal mediator essential for anaphylaxis. The other important mediators which are released include neutrophil and eosinophil chemotactic factors (NCF-A, ECF-A), slow reacting substance of anaphylaxis (SRS-A), platelet activating factor (PAF), and prostaglandins.

\section{Histamine}

In man, two distinct classes of histamine receptor sites $\left(\mathrm{H}_{1}\right.$ and $\left.\mathrm{H}_{2}\right)$ have been identified. Stimulation of the $\mathrm{H}_{1}$ receptors results in smooth muscle contraction of the respiratory and the gastrointestinal tracts, enhanced exocrine gland secretion, and increased vascular permeability that promotes oedema formation by opening the gaps between endothelial cells of the post-capillary vessels. In contrast, stimulation of the $\mathrm{H}_{2}$ receptors affects predominantly gastric acidity and cardiac function. The $\mathrm{H}_{2}$ receptors in atrial and ventricular myocardium mediate positive chronotropic and inotropic responses, similar to beta-adrenergic receptors. ${ }^{15-17}$ The deleterious cardiovascular effects of histamine include hypotension secondary to venodilation and a sudden decrease in left ventricular filling, ${ }^{18}$ coronary vasoconstriction, ${ }^{19}$ increased myocardial oxygen demand from enhanced inotropy, chronotropy and arrhythmias. ${ }^{20}$

\section{Eosinophil chemotactic factor of anaphylaxis (ECF-A)}

Eosinophils are intimately associated with im- mediate hypersensitivity reactions. The term "eosinophil chemotactic factor of anaphylaxis" was first used in 1971 to describe a mediator that specifically attracted eosinophils. ${ }^{21}$ Eosinophils contain a number of enzymes capable of neutralizing the effect of various mediators released during anaphylactic reactions. These reactions include inactivation of histamine, slow reacting substance of anaphylaxis (SRS-A), and platelet activating factor (PAF), by the eosinophil liberated enzymes histaminase, arylsulphatase $B$ and phospholipase $D$, respectively.

In addition to "turning off" the allergic inflammatory reaction, eosinophils have also been shown to phagocytose antigen-antibody complexes. Mast cells and basophils also release neutrophil chemotactic factor which is selective for stimulating chemotactic migration of neutrophils.

Slow-reacting substance of anaphylaxis (SRS-A) and leukotrienes

The complate structure of SRS-A, a potent biologic mediator, derived from arachidonic acid, was not identified until 1979. ${ }^{22}$ The name leukotrienes has been given to these mediators since they are produced by leucocytes and contain a conjugated triene. These mediators have a unique ability to specifically produce contraction of smooth muscle in the small airways. They cause dose-dependent long-lasting contraction of rat and human pulmonary smooth muscle, this effect being exerted preferentially on the peripheral compared to the central airways. Furthermore, the contraction produced is 200-to 20,000-fold greater in intensity than that produced by histamine. These mediators also produce systemic arterial hypotension by increasing capillary permeability.

\section{Platelet activating factor (PAF)}

Following IgE dependent activation of mast cells and basophils, this newly synthesized mediator (PAF) is released. The platelet activating factor causes vasoactive amine release from the platelets in addition to platelet aggregation.

\section{Prostaglandins}

These 20-carbon unsaturated hydroxy acids are derived from arachidonic acid. Human mast cells have been shown to produce the prostaglandins $D_{2}$, $E_{1}, E_{2}$ and $F_{2}$. Prostaglandins $P G E_{1}$ and $P_{G E}$ cause bronchodilation whereas $\mathrm{PGD}_{2}$ and $\mathrm{PGF}_{2} \alpha$ 
produce a bronchoconstriction in the human being. ${ }^{23}$ These and other chemical mediators are responsible for the clinical manifestations in anaphylactic and/or anaphylactoid types of allergic responses.

\section{Clinical manifestations}

The symptom complex of an allergic reaction may involve the skin, the cardiovascular system, the respiratory tract, the eye, and the gastro intestinal tract, either singly or in combination. The severity of the symptoms, the onset of the reaction and the duration of reaction are extremely variable. The onset of symptoms following intravenous administration of an antigen occurs abruptly, within 2 to 11 minutes, reaching a peak at 5 to 60 minutes. The oral ingestion of the antigen on the other hand may precipitate symptoms hours later, although affliction within minutes is also possible. ${ }^{24}$ The usual order of involvement of various organs in an allergic reaction is skin changes, hypotension with tachycardia and arrhythmias, bronchospasm and laryngeal oedema with resulting arterial hypoxaemia. While skin changes and mild respiratory reactions are the most common clinical manifestations, severe respiratory distress from bronchial obstruction and/or laryngeal oedema, along with severe hypotension are the prominent features in fatal episodes.

\section{Skin}

The characteristic skin lesions in an allergic reaction are well circumscribed discrete wheals, with erythematous, raised, serpiginous borders and blanched centres. These urticarial eruptions are intensely pruritic, with a diffuse or a localized distribution to the face, chest and upper arms, and may coalesce to form giant hives that seldom persist beyond 48 hours. The oedema of the eyelids may be prominent along with lacrymation, occular itching and conjunctivitis. These skin manifestations are due to the release of chemical mediators from mast cells. The classic triad of erythema, wheal and flare response results from the mediator-provoked capillary dilatation, increased vascular permeability and the stimulation of the axon reflex respectively.

\section{Cardiovascular system}

Cardiovascular homeostasis may be severely affected by the release of chemical mediators such as histamine. Hypotension and vascular collapse may result from acute reduction in intravascular fluid volume as a result of histamine-induced increases in capillary permeability and subsequent extravascular translocation of fluids. Venous pooling due to relaxation of vascular smooth muscle may further aggravate the hypotension culminating in a vascular collapse. Tachycardia accompanying hypotension is most likely due to the chronotropic effects of endogenous catecholamine release from the adrenals and the sympathetic ganglia. ${ }^{25}$ In addition, localised cardiac histamine release may cause myocardial damage, ${ }^{26}$ arrhythmias and/or conduction delay, and epicardial coronary vasoconstruction through a stimulation of the $\mathrm{H}_{1}$ receptors.

\section{Respiratory system}

Histamine-mediated respiratory smooth muscle $\mathrm{H}_{1}$ receptor stimulation produces bronchoconstriction and obstruction, with cough and audible wheeze. Presence of laryngeal oedema with or without bronchial obstruction may lead to severe arterial hypoxaemia, pulmonary oedema and death. In fatal cases with clinical bronchial obstruction, the lungs exhibit marked hyperinflation with microscopic evidence of luminal secretions, peribronchial congestion, submucosal oedema, eosinophilic infiltration, and acute emphysema attributable to intractable bronchospasm.

\section{Gastrointestinal and other organ systems}

Gastrointestinal manifestations include nausea, vomiting, abdominal pain of a crampy nature and blood diarrhoea. In addition, allergic reactions may also cause coagulation defects, leucopenia, and a reduction in body temperature. The severity of these symptoms may be modified by different anaesthetic agents; however, there is no evidence to suggest that either general ${ }^{27}$ or regional ${ }^{28}$ anaesthesia may afford a protection against occurrence of an allergic reaction. On the contrary, it is possible that regional analgesia, by producing sympathetic block, may potentiate histamine-induced hypotension, and thus enhance morbidity or mortality of an allergic reaction.

\section{Diagnosis}

In most cases the diagnosis of drug allergy is based upon a temporal association of an adverse reaction 
with the administration of a drug. However, such a diagnosis of allergy is presumptive and "true allergy" can be established only after confirmation of an immunological basis. In order to establish the mechanism and the agent responsible for an allergic reaction, several tests should be carried out and their results considered in relation to the clinical features. The methods for investigating allergic reactions include allergy skin test, plasma $\operatorname{IgE}$ antibody and complement proteins $\mathrm{C}_{3}$ and $\mathrm{C}_{4}$ levels, plasma histamine levels, leucocyte histamine release test, IgE inhibition test and radio allergosorbent tests.

Measurements of plasma histamine levels provide a direct measure of the release of effector substance, but fail to elucidate the mechanism responsible for the reaction. Presence of elevated IgE antibodies along with a positive skin test demonstrate previous sensitization. The complement and histamine measurements at the time of a reaction indicate the mechanism of reaction. In contrast the leucocyte histamine release test and the radio allergosorbent test help identify the causative agent. Following a suspected allergic reaction, a detailed clinical history with reference to previous single or multiple exposures to the drug, the patient's immune status and his "degree of stress" (viral infection, chronic inflammation, preoperative apprehension and fear) should be reviewed and serial measurements of plasma IgE, and complement $\mathrm{C}_{3}$ and $\mathrm{C}_{4}$ should be made. Ideally the first sample of venous blood should be taken within 30 minutes of reaction and subsequent samples at 3,6 , 12 and 24 hours respectively. ${ }^{29,30} \mathrm{~A}$ further sample taken three to five days after the event provides a normal baseline for the patient. Where facilities are available serial plasma histamine levels should also be measured as described by Lorenz et al. ${ }^{31}$ Fluorimetric techniques allow plasma histamine measurements, the normal levels being $0.2-1.0$ $\mathrm{ng} \cdot \mathrm{ml}^{-1}$. Values above $2 \mathrm{ng} \cdot \mathrm{ml}^{-1}$ are associated with flushing and urticaria, while plasma levels above $5.0 \mathrm{ng} \cdot \mathrm{ml}^{-1}$ are associated with severe clinical manifestations and profound hypotension.

In anaphylactic or Type I hypersensitivity response there is usually a history of previous exposure to the drug, and within one hour after an anaphylactic reaction there is a sudden decrease in the plasma IgE levels reflecting a binding of the antibody to the allergenic drug. This initial decrease is later followed by a marked elevation in the antibody IgE level.

Previous exposure to the drug(s) is necessary in humoral antibody (IgG, IgM) mediated reactions with classical complement system activation. Serial plasma samples in this case will reveal complement $\mathrm{C}_{3}$ and $\mathrm{C}_{4}$ consumption of varying degrees, the consumption of $\mathrm{C}_{3}$ generally being less than 30 per cent. In contrast, high levels of complement $\mathrm{C}_{3}$ conversion (30-70 per cent), without $C_{4}$ conversion, are observed in reactions following alternative pathway activation of the complement system. An anaphylactoid reaction may occur following the first exposure to the drug without any changes in antibody IgE levels or complement $\mathrm{C}_{3}$ and $\mathrm{C}_{4}$ levels.

After full recovery, the patient should be referred to an experienced clinical immunologist where comprehensive details of the adverse incident, drugs administered and their sequence, stress, atopy and other inherent risk factors can be assessed. On the basis of this evaluation, in vivo, allergy skin tests, as well as the in vitro leucocyte histamine release test should be conducted in order to identify the drug responsible for the reaction. ${ }^{32}$

\section{Investigation}

\section{Allergy skin testing}

The allergy skin test is simple, inexpensive, and the only in vivo test for confirming $\operatorname{IgE}$ antibody mediated drug reactions. Despite controversy over its diagnostic value, safety, and ability to elucidate a mechanism, this test is more valuable than other tests in detecting the agent responsible for a reaction. ${ }^{33}$

Patients should be tested approximately a month after the reaction and should be off all drugs which may modify the response. Drug(s) under investigation are diluted in normal saline (1:1000 dilution usually) and 0.01 to $0.02 \mathrm{ml}$ are injected intradermally to raise a $1-2 \mathrm{~mm}$ wheal on the medial aspect of the forearm. Since diluents or preservatives in commercial preparations may also act as allergens, tests using the diluent or the preservative separately are also required. Since localized histamine release due to the trauma of injection may cause a wheal through dermographism, a control intradermal injection of normal saline must be included in order to avoid a false positive interpretation through der- 
mographism. ${ }^{34} \mathrm{~A}$ wheal greater than $1.0 \mathrm{~cm}$, appearing within ten minutes and persisting for at least 30 minutes, is generally accepted as a positive response. However, the following abnormal responses also constitute valid and reliable criteria for a positive response in a standardized test procedure. $^{33}$

- Wheals greater than $7.0 \mathrm{~mm}$, when they persist in serial dilutions and if pseudopod formation is also present.

- Large flares which persist 30 minutes in serial dilutions.

- Generalized cutaneous itching in the absence of wheal and flare responses, if they can be shown to occur only with one drug.

- Wheals of greater than $0.8 \mathrm{~mm}$ arising three to four hours after testing.

A false negative intradermal test may occur if degradation of the drug to an antigen or its conjugation to a carrier protein were not possible at the injection site. Although relatively minute amounts of drugs are utilized during the intradermal test, systemic anaphylaxis can still occur and appropriate resuscitative measures and drugs should always be readily available.

A variation of the intradermal test (PrausnitzKustner test ${ }^{35}$ ) utilizes intradermal injection of plasma from an allergic patient into a non-allergic person and subsequently intradermal injection of the suspected drug at the same site. A wheal and flare response should occur within 20 minutes if antibodies to the drug were present in the patient's plasma sample. Because of the possible transmission of viral hepatitis this test has largely been abandoned.

\section{Leucocyte histamine release test ${ }^{36,37}$}

This test utilizes the ability of an allergenic drug to degranulate and release histamine from leucocytes in vitro. This test is particularly useful in establishing a diagnosis of anaphylactoid response when the evidence for immunologic system involvement is lacking. The leucocytes obtained from the patient on incubation with the serial dilutions of the suspected drug should cause an increased histamine release in a dose-dependent manner. The test is laborious and difficult and at present is mainly a research instrument.

$\lg E$ inhibition test $^{38}$

In this test the principle of specificity of binding between the specific antibody and the antigenic drug that stimulated the formation of the antibody is utilized. The patient's plasma containing the antibody $\operatorname{IgE}$ is incubated with the suspected drug, the antigen-antibody complex is formed with the resultant decrease in the IgE levels. Again, this test is not routinely available, is expensive and difficult to perform.

\section{Radioallergosorbent test (RAST) ( $^{39.40}$}

This radioimmunoassay estimates the amounts of antibodies specific for an antigen or a drug. The antibody content of a serum can be assessed by its ability to bind to the antigen which has been rendered insoluble by coupling to an immunoadsorbent. Initially an antigen-antibody complex is formed by adding commercial antigen to the patient's plasma. The radioactivity of the antigenantibody complex following the addition of antiIgE will correlate with the in vivo oncentration of drug-specific IgE antibodies. Although the test is specific and sensitive for $\mathrm{IgE}$ mediated type I hypersensitivity, its usefulness as a diagnostic tool has been limited by the non-availability of the specific drugs as a commercially prepared antigen. False positive results may also occur in patients with high nonspecific serum IgE levels. Despite these limitations it is a useful diagnostic test of drug induced anaphylaxis.

Anaesthetic drugs that induce allergic reactions A large spectrum of anaesthetic drugs as well as other agents such as antibiotics, blood products, volume expanders, radiocontrast dyes and chymopapain have been known to initiate an allergic response. The clinical manifestations and their treatments are essentially identical irrespective of the reaction being anaphylactic or anaphylactoid.

\section{Narcotics}

Narcotics may stimulate anaphylactoid reactions with a direct release of histamine from basophils and mast cells. Morphine produces erythema along the vein and may cause orthostatic hypotension by histamine induced peripheral vasodilation. True anaphylactic type responses are extremely rare with morphine. However, following administration of meperidine, anaphylactic reactions with urticaria, bronchospasm, hypoxaemia and hypotension and subsequent IgE antibody demonstration, have been previously reported. ${ }^{41}$ Synthetic narcotics such as 
fentanyl, sufentanil, and alfentanil can produce histamine induced bronchospasm and vasodilatation, but true anaphylaxis or anaphylactoid reactions have not been reported following their administration.*

\section{Intravenous induction agents}

\section{BARBITURATES}

Both anaphylactic ${ }^{42}$ and anaphlactoid type drug reactions have been reported following the administration of thiopentone and methohexitone. ${ }^{43}$ The incidence of these reactions has been variously estimated to be 1 in 1400 for thiopentone, ${ }^{44}$ and 1 in 7000 for methohexitone. ${ }^{45}$ However, on critical appraisal of the literature, an overall incidence of 1 in 30,000 would appear to be more realistic. ${ }^{30}$ To date six deaths have been reported following thiopentone administration. ${ }^{46}$ These allergic reactions are more common in patients with atopy, allergies to food, and seasonal allergies. The frequency and the time interval between administration of the drugs play an important role in the pathogenesis of allergic reactions. In susceptible patients even oral administration of amylbarbitone can produce an allergic response following previous sensitization by thiopentone. ${ }^{47}$ Both regional and general anaesthesia may potentiate the histamine induced hypotension by further vasodilation and impared catecholamine release, through peripheral sympathetic nervous system block. Histamine induced bronchospasm may also remain refractory to treatment with a bronchodilator during an allergic response to barbiturates. ${ }^{43}$ The mechanism underlying the reaction is often difficult to elucidate because of the multiplicity of drugs used during clinical anaesthesia and therefore a thorough history along with a complete physical and laboratory examination is required to understand the pathogenesis of the drug reaction.

\section{ALTHESIN AND PROPANIDID}

The incidence of allergic reactions with althesin is much higher ( 1 in 930$)^{44}$ than with thiopentone although the latter carries a higher mortality. The

*Since the acceptance of this manuscript an anaphylactic drug reaction to fentanyl, substantiated by a positive intradermal skin test to serial dilutions of the drug has also been reported. Can Anaesth Soc J 1986, 33 : 75-8. incidence of allergic reactions with propanidid has been reported as 1:540. ${ }^{48}$ The higher incidence of allergic reactions to these drugs has been attributed to the solvent cremophor EL. ${ }^{49}$ A memory mediated reaction, involving complement activation by the classical and/or alternate pathways, with the liberation of anaphylatoxin $\mathrm{C}_{3 \mathrm{a}}$ and the resulting granulocyte margination, are an integral part of the allergic process. There is an initial neutropenia due to the cremophor-mediated increase in the adherence of the granulocytes to vessel walls, which is subsequently replaced by marked neutrophilia. The role of cremophor in the allergic reactions gains further credibility when one observes a higher incidence of drug reactions following diazepam administration where the adjuvant cremophor had been substituted for propylene glycol. ${ }^{50}$ It is suggested that the detergent properties of the cremophor may impart immunogenicity. ${ }^{51}$ The clinical features of the reaction in order of frequency include skin changes, hypotension, bronchospasm and abdominal symptoms. The mechanism responsible for these reactions should be established by serial measurements of complement $C_{3}$ and $C_{4}$, along with changes in the antibody and the leucocyte counts during the reaction.

\section{KETAMINE}

Anaphylactoid reactions without hypotension or bronchospasm, but with a macular rash have been reported following ketamine administration. A negative P-K test, despite prior exposure to ketamine would further suggest an anaphylactoid origin in such reactions. ${ }^{52}$

\section{ETOMIDATE}

Reactions to etomidate differ from those to the other induction agents in that the symptoms are predominantly cutaneous or gastrointestinal and the more hazardous cardiovascular and respiratory manifestations are lacking. ${ }^{53}$

\section{Local anaesthetics}

True allergic reactions to local anaesthetics are rare, accounting for less than one per cent of all adverse reactions to these agents. ${ }^{54}$ Although an allergic response to the amide group of agents has occasionally been documented, the incidence of allergy is mostly confined to the ester type local anaesthetics that produce metabolites related to the highly antigenic compound para-aminobenzoic acid. 
Local anaesthetic solutions may contain methylparaben, a preservative with bacteriostatic and fungistatic properties. Methylparaben is an alkyl ester of parahydroxy benzoic acid and its structural similarity to para-aminobenzoic acid renders it antigenic. As a result, hypersensitivity reaction may occur due to prior stimulation of the antibody production by the preservative itself. In addition to methyl paraben, bisulfite sensitivity may also manifest as allergy to local anaesthetics. ${ }^{55}$ Allergic reactions to local anaesthetics must be carefully distinguished from the inadvertent intravascular injections as well as their cardiotoxic effect, which have generated considerable concern regarding their safety. ${ }^{56}$ Suspected allergic reactions to local anaesthetics should be investigated by immunological and skin testing procedures with the pure drug as well as the preservative.

\section{Muscle relaxants}

Allergic reactions to muscle relaxants occur more commonly than has been previously suspected. ${ }^{57}$ Both anaphylactic and anaphylactoid reactions have been observed; however, cross-sensitivity between muscle relaxants has not been reported. Patients with previous allergy, atopy, asthma, and prior reactions to anaesthesia, have a significantly higher incidence of allergic reactions to muscle relaxants. ${ }^{58}$ There is also a preponderance of female patients having allergic reactions to the muscle relaxants. ${ }^{59}$ Patients with allergy to penicillin and cosmetics appear to react to muscle relaxants with greater frequency ${ }^{60}$ The possibility of sensitivity to cosmetics predisposing in reactive patients provides a possible explanation for preponderance of female patients reacting to muscle relaxants. Sensitivity to more than one muscle relaxant may occur and has been shown for alcuronium and d-tubocurarine, ${ }^{61}$ and succinylcholine, gallamine, decamethonium, and fazadinium. ${ }^{62}$ The mechanism of reaction to muscle relaxants remains unclear, and despite absence of previous exposure to the drug, the clinical features of bronchospasm, cardiovascular collapse, angioneurotic oedema, along with positive evidence of $\mathrm{P}-\mathrm{K}$ and $\mathrm{IgE}$ mediated reaction represent a Type I hypersensitivity or anaphylaxis.

The role of preservatives and additives in reactions to succinylcholine has been discussed and speculated upon by Morrow. ${ }^{63}$ Since the liquid form only and not the powder form of succinylcholine contains methylparaben, this preservative should be taken into consideration when skin testing with the liquid succinylcholine. As with the local anaesthetics, an allergic response following succinylcholine may, in fact, be due to the preservative rather than the drug itself. Also, the bronchospasm observed may well be due to intubation and light anaesthesia rather than to an allergic response. A direct release of histamine from mast cells and basophils following quaternary ammonium compounds has been shown to occur both systemically and cutaneously, with all muscle relaxants currently in use. ${ }^{59}$

\section{Antibiotics}

Intravenous administration of antibiotics during surgery is common and allergic reactions after such administration have been reported with different subclasses of antibiotics. While allergic reactions to penicillin are well established, its cross-sensitivity with cephalosporins should also be recognized. ${ }^{64}$ Similarly, adverse reactions and cross-sensitivity between aminoglycosides such as vancomycin and other para-amino benzoic acid derivatives should also be borne in mind. Recently both anaphylactic and anaphylactoid responses have been reported following intravenous vancomycin therapy. ${ }^{65}$ Even without a true allergic response, rapid intravenous infusion of vancomycin may cause up to a 50 per cent fall in the systolic blood pressure; the mechanism responsible for this is not clear. ${ }^{66}$

\section{Chymopapain}

Chymopapain injections have been shown to be effective for the relief of pain from a herniated lumbar disc. However, allergic reactions of varying severity including cardiovascular collapse and death, with an estimated incidence of 0.82 per cent have been associated with these injections. These allergic reactions appear to be more common in women, in patients with multiple allergies, and in patients with allergies to papaya or papaya derivatives. ${ }^{67}$ Allergy skin testing is a reliable way to predict patients likely to develop an allergic reaction to chymopapain. Premedication with $\mathrm{H}_{1}$ and $\mathrm{H}_{2}$ receptor blockers and high-dose steroids have also been found to decrease the incidence and severity of allergic reactions. Although several anaesthetic techniques have been utilized, invasive arterial pressure monitoring along with endotracheal anaesthesia may be a prudent precaution in susceptible patients. ${ }^{68}$ 


\section{Intravascular contrast media}

Approximately five per cent of the radiological studies utilizing intravascular contrast media are complicated by adverse systemic reactions of which one-third are severe. ${ }^{69}$ Several factors may influence the risk of a reaction. A history of atopic disease, seafood hypersensitivity and asthma, can increase the risk of a reaction by 10 to 15 per cent. ${ }^{70}$ Anaphylactoid reactions have been known to occur in all age groups including infants, though the number of these reactions are disproportionately higher in the third and fourth decades of life. There is no gender bias, but the patients with cardiac disease are four to five times more likely to have a systemic reaction. The dose and the manner of the dye injection also influence the risk. Distinctly fewer reactions occur at a dose of less than $20 \mathrm{~g}$ iodine which roughly approximates to $50 \mathrm{ml}$ of a particular contrast compound. ${ }^{71}$ The reaction may manifest as vasomotor, vasovagal, dermal, osmotic and anaphylactoid. Most severe reactions are idiosyncratic and the history of reaction to contrast media may not predict the current response. Acquisition of a knowledge of their pathogenesis and treatment may help prevent and decrease the morbidity and mortality of these reactions. ${ }^{72}$

\section{Plasma volume expanders}

Plasma protein solutions as well as synthetic plasma substitutes have been implicated in the initiation of anaphylactic or anaphylactoid responses. The incidence of severe reactions was estimated as 0.003 per cent following administration of plasma protein solutions, while dextran, gelatin and hydroxyethyl starch solutions respectively produced adverse reactions in $0.008,0.038$ and 0.006 per cent of the patients. ${ }^{73}$ The reactions to dextran are more common in males, whereas female patients in the perinatal period are more susceptible to modified gelatin solutions. Increasing volume, concentration and the rate of infusion may also increase direct histamine release. Depending on the severity of the reaction, the symptoms may be classed as Grade I with skin manifestations alone; Grade II - with moderate hypotension, nausea and respiratory distress; Grade III - with severe hypotension, shock and bronchospasm; and Grade IV - cardiac and/or respiratory arrest.

Rapid infusion of plasma protein fraction can produce flushing, a feeling of fullness in the head, constricting chest pain, abdominal and back pain, apprehension and hypotension. Plasma protein fraction preparations may contain prekallikrein activators which may be responsible for activation of kallikrein-kinin system following intravenous infusion of these solutions. ${ }^{74}$ The high levels of kinin activity may be responsible for these reactions. Sodium acetate in plasma protein solutions may also cause hypotension by vasodilatation. Low molecular weight dextrans cannot induce antibody formation, but may react with preformed antidextran antibodies following prior exposure to polysaccharides of viral or bacterial origin. These antibodies belong to the IgG and IgM classes and there is no evidence of IgE activity. There is evidence that dextran may activate the altemate pathway of the complement system with formicion of cleavage products of $\mathrm{C}_{2}, \mathrm{C}_{3}$ and $\mathrm{C}_{5}$, which in turn produce the symptoms of an allergic reaction. These plasma volume expanders should be used with caution in patients susceptible to an allergic reaction.

\section{Blood}

Manifestations of an allergic reaction to blood transfusion may vary from pruritis, erythema, urticaria and raised body temperature to an abrupt onset of pulmonary oedema in the absence of fluid overload or cardiac dysfunction. Incompatible plasma proteins may initiate the release of histamine from mast cells and basophils with manifestations of an allergic reaction. These reactions have occurred in three per cent of patients receiving properly typed and cross-matched blood. ${ }^{75}$

\section{Protamine}

Protamine, a polycationic polypeptide derived from salmon sperm, frequently used for neutralization of heparin during surgery and blood component donation, may produce an anaphylactic-type reaction. Both in dog and in man, protamine causes a decrease in systemic vascular resistance with a fall in cardiac output and a concomitant increase in pulmonary artery pressure by releasing histamine and other vasoactive substances from the platelets and the mast cells as well as by the activation of the complement system through the classical pathway. Patients with allergy to fish and seafood are more at risk of having an anaphylactic reaction on exposure to protamine. ${ }^{76}$ Similarly, diabetic patients on protamine zinc insulin therapy may stimulate the production of IgE antibodies, and subsequent exposure to protamine can cause an allergic reaction by 
degranulation and release of vasoactive chemicals from mast cells and basophils. The vasectomized patients, theoretically, may also be at an enhanced risk of sensitivity to protamine due to the sperm autoantibody formation. ${ }^{37}$ In susceptible patients a test dose of $5-10 \mathrm{mg}$ of intravenous protamine has been recommended. ${ }^{78}$

\section{Rationale of drug therapy}

The objective of the drug therapy in anaphylaxis is firstly to prevent and/or attenuate the release of chemical mediators from mast cells and basophils, and secondly, to abolish or curtail the severity of the non-physiologic response to these chemical mediators. The release of chemical mediators is encouraged by a fall in the intracellular cAMP or a rise in cGMP concentrations, whereas high concentrations of cAMP stabilize the target cells against degranulation. The drugs considered in the treatment of allergic reactions include the adrenergic agents, the methylxanthines, the antihistamines, and the corticosteroids.

The adrenergic drugs with $\beta$-agonist activity, such as epinephrine and isoproterenol, tend to stabilize the target cells by increasing the intracellular CAMP, and prevent the progression of anaphylaxis by decreasing the release of histamine and SRS-A. Furthermore, the $\beta$-adrenergic stimulation also reverses the mediator induced bronchoconstriction. The $\alpha$-agonists such as norepinephrine, phenylephrine tend to decrease cAMP and increase the mediator release, and therefore should only be used to maintain perfusion pressure in the presence of severe refractory hypotension.

The methylxanthines inhibit the degradation of cAMP by phosphodiesterase with the resultant increase in the intracellular cAMP levels. This increase in the cAMP causes a decreased release of histamine and SRS-A following an antigenic drug challenge. These agents are also potent bronchodilators for antigen or histamine induced bronchospasm; however, it is unknown whether or not the effectiveness of these agents is based on changes in cAMP. Because of their unpredictable cardiovascular effects and possible potentiation of hypotension, they should only be used to treat bronchospasm refractory to epinephrine therapy.

Antihistamines act as competitive inhibitors of histamine at the target cell receptors. Since histamine is the cardinal offending chemical mediator in human anaphylaxis, these drugs should be used in all forms of anaphylaxis. Although $\mathbf{H}_{1}$ receptor blocking drugs, such as diphenhydramine, may help to reverse the effects of histamine at $H_{1}$ receptor sites in the smooth muscle of the lungs, vascular tree and the gastro-intestinal tract, the $\mathrm{H}_{2}$ receptors in the heart and the stomach may also need to be blocked by drugs like cimetidine in the presence of arrhythmias and hypotension.

Corticosteroids have also been recommended for use in acute anaphylaxis. They have neither an adverse effect, nor are they contraindicated in acute anaphylaxis, and may be useful in persistent hypotension and bronchospasm. However, there is little or no evidence that they can act sufficiently rapidly to reverse acute anaphylaxis that may progress from onset to death in minutes.

\section{Management of anaphylaxis}

The manifestations of anaphylaxis may vary from mild urticaria and pruritis to a life-threatening reaction with bronchospasm and hypotension. Therapy depends on the severity and manifestations of the reaction. Therapy should be titrated to the desired effects with appropriate monitoring and severe reactions may require aggressive therapy with larger doses of medications. An outline of a protocol for the management of anaphylaxis is listed in the Table.

\section{Prevention of allergic drug reactions}

The factors predisposing to allergic drug reactions are obviously closely linked to prevention. History of chronic atopy, asthma, hay fever, drug allergies and food sensitivities should be sought at the time of the preoperative visit since their presence will make a patient more prone to an allergic reaction. In addition, repeated and multiple exposures to the same or similar drugs also enhances the incidence of allergic reactions. Similarly, drugs with adjuvants and preservatives have the potential to initiate an allergic response. The interval between exposures is also important since a time interval of two weeks is deemed optimal for development and expression of drug allergy.

Preoperative preparation of patients who are susceptible to an allergic response should include an $\mathrm{H}_{1}$ receptor antagonist (diphenhydramine 0.5-1.0 $\mathrm{mg} \cdot \mathrm{kg}^{-1}$ ) and an $\mathrm{H}_{2}$ receptor antagonist (cimetidine 4-6 $\mathrm{mg}^{\circ} \mathrm{kg}^{-1}$ ) PO. Since stress has been known to 
TABLE Protocol for management of anaphylaxis

\begin{tabular}{|c|c|c|}
\hline Reaction & Immediate treatment & Secondary treatment \\
\hline $\begin{array}{l}\text { Mild } \\
\text { Conjunctivitis } \\
\text { Uricaria } \\
\text { Pruritis } \\
\text { Erythema }\end{array}$ & $\begin{array}{l}\text { Prompt discontinuation of the } \\
\text { allergenic drug } \\
\text { Airway maintenance with } 100 \% \text { oxygen } \\
\text { Epincphrine } 0.3-0.5 \mathrm{mg} \mathrm{IM} \\
(0.3-0.5 \mathrm{ml} \text { of } 1: 1000 \text { solution) } \\
\text { Diphenhydramine } 50 \mathrm{mg} \mathrm{IM} \\
\text { Monitor BP, pulse and respiration }\end{array}$ & Diphenhydramine $50 \mathrm{mg}$ orally every six hours \\
\hline $\begin{array}{l}\text { Severe } \\
\text { Laryngeal oedema } \\
\text { Bronchospasm } \\
\text { Hypotension }\end{array}$ & $\begin{array}{l}\text { Stop allergenic drug } \\
\text { Airway maintenance with endotracheal } \\
\text { intubation if necessary and } \\
100 \% \mathrm{O}_{2} \text { therapy } \\
\text { Epinephrine IV } 5 \mu \mathrm{g} \cdot \mathrm{kg}^{-1} \text { titrated to } \\
\text { desired effect } \\
\text { Volume expansion with } 1-2 \text { litres of } \\
\text { crystalloids or colloids }\end{array}$ & $\begin{array}{l}\text { Diphenhydramine IV } 0.5-1.0 \mathrm{mg} \cdot \mathrm{kg}^{-1} \text {. If hypotension } \\
\text { present add cimetidine } 4 \mu \mathrm{g} \cdot \mathrm{kg}^{-1} \text { IV. } \\
\text { IV aminophylline ( } 3-5 \mathrm{mg} \cdot \mathrm{kg}^{-1} \text { ) if bronchospasm severe } \\
\text { and persistent } \\
\text { Sympathomimetics only if necessary to maintain } \\
\text { perfusion pressure } \\
\text { Norepinephrine } 1-2 \mu \mathrm{g} \cdot \mathrm{min}^{-1} \\
\text { Isoproterenol } 0.5-1.0 \mu \mathrm{g} \cdot \mathrm{min}^{-1} \\
\text { Corticosteroids } \\
\text { Hydrocortisone } 1 \mathrm{~g} \text { IV or methylp to } \\
\text { if complement activation is suspected } \\
\text { Monitor } \\
\text { - EKG } \\
\text { - Blood Pressure } \\
\text { - Blood Gases } \\
\text { - Urinary output } \\
\text { - CVP/or pulmonary capillary pressure (rarely required) } \\
\text { Bicarbonate to correct acidosis }\end{array}$ \\
\hline
\end{tabular}

induce respiratory distress, premedication with benzodiazepines may be useful. Administration of disodium cromoglycate is desirable in patients with atopy. Patients with a history of allergic reactions to radiographic contrast media, should receive prednisone $50 \mathrm{mg}$ PO every six hours for one day, with the last dose given one hour prior to the procedure, along with diphenhydramine $50 \mathrm{mg}$ IM. This regimen has been shown to decrease the incidence and the severity of allergic reactions to the radiographic contrast media.

Since the magnitude of histamine release during an allergic reaction is related to the dose of the drug and its administration, rapid intravenous administration of drugs should be avoided.

A careful history of previous drug reactions, adequate and appropriate preoperative preparation, a knowledge of drugs with a potential for allergic reactions, the safer routes and speed of drug administration, may all help reduce the incidence of allergic drug reactions. Therefore, a detailed con- sideration of preventive measures is warranted in order to reduce the morbidity and mortality from allergic drug reactions.

\section{Acknowledgements}

The author thanks Dr. J. Dolovich, Professor of Paediatrics, and Dr. D. P. Singal, Professor of Pathology, for their valuable critique of the manuscript. Also, I wish to thank Mrs. Valerie Cannon for her expert secretarial assistance.

\section{References}

1 Van Arsdel PP. Diagnosing drug allergy. JAMA 1982; 247: 2576-81.

2 Watkins J. Anaphylactoid reactions to IV substances. Br J Anaesth 1979; 51: 51-60.

3 Jawetz $E$. Review of medical microbiology. Los Altos, California: Lang Medical Publications, 1972.

4 Parker $C W$. Hapten immunology and allergic reactions in humans. Arthritis Rheum 1981; 24: 102436. 
5 Parker CW. Drug allergy. N Engl J Med 1975; 242: 732-6.

6 Coombs RRA, Gell PGH. Clinical Aspects of Immunology. Oxford, England: Blackwell Scientific Publications, 1963.

7 Conrad DH, Froese A. Characterization of the target cell receptor for IgE. II. Polyacrylamide gel analysis of the surface $\mathrm{IgE}$ receptor from normal rat mast cells and from rat basophilic leukocytes. J Immunol 1976; 116: 319-26.

8 Sullivan AL, Grimley PM, Metzger $H$. Electron microscopic localization of immunoglobulin $E$ on the surface membrane of human basophils. J Exper Med 1971; 134: 1403-16.

9 Ishizaka $T$, Soto $C$, Ishizaka $K$. Mechanisms of passive sensitization. III. Number of IgE molecules and its receptor sites on human basophil granulocytes. J Immunol 1973; 111: 500-11.

10 Stoelting $R K$. Allergic reactions during anaesthesia. Anesth Analg 1983; 62: 341-56.

11 Hugli TE, Muller-Eberhard HJ. Anaphylatoxins: $\mathrm{C}_{3 \mathrm{a}}$ and $\mathrm{C}_{5 \mathrm{a}}$. Adv Immunol 1978; 26:1-53.

12 Moss J, Rosow CE, Savarese JJ, Philbin DM, Knif$f e n K J$. Role of histamine in the hypotensive action of d-tubocurarine in humans. Anesthesiology 1981; 55: 19-25.

13 Rosow CE, Moss J, Philbin DM, Savarese JJ. Histamine release during morphine and fentanyl anaesthesia. Anesthesiology 1982; 56: 93-6.

14 Altman $L C$. Basic immune mechanisms in immediate hypersensitivity. Med Clin North Am 1981; 65: 941-57.

15 Levi $R$, Hordof A, Edie R, Rosen M. Histamine effects on human atria (Abstract). Circulation 1978; 57, 58: Suppl II: ii-105.

16 Ginsburg R, Bristow MR, Stinson EB, Harrison $D C$. Histamine receptors in the human heart. Life Sci 1980; 26: 2245-9.

17 Gristwood RW, Lincoin JCR, Owen DAA. Effects of histamine on human isolated heart muscle: comparison with effects of noradrenaline. J Pharm Pharmacol 1980; 32: 145-9.

18 Bristow MR, Sageman WS, Scott RH et al. Acute and chronic cardiovascular effects of doxorubicin in the dog: the cardiovascular pharmacology of druginduced histamine release. J Cardiovasc Pharmacol 1980; 2: 487-515.

19 Levi R. Effects of exogenous and immunologically released histamine on the isolated heart: a quantita- tive comparison. J Pharmacol Exp Ther 1972; 182: $227-45$.

20 Levi $R$, Zavecz $J H$. Acceleration of idioventricular rhythms by histamine in guinea pig heart. Mediation by $\mathrm{H}_{2}$ receptors. Circ Res $1979 ; 44: 847-55$.

21 Kay $A B$, Stenchschulte DJ, Austen $K F$. An eosinophil leukocyte chemotactic factor of anaphylaxis. J Exp Med 1971; 133: 602-19.

22 Murphy RC, Hammarstrom S, Samuelsson B. Leukotriene C: a slow-reacting substance from murine mastocytoma cells. Proc Natl Acad Sci 1979; 76: 4275-9.

23 Kuehl FA Jr, Egan RW. Prostaglandins, arachidonic acid and inflammation. Science 1980;210: 978-84.

24 Kelly $J F$, Patterson R. Anaphylaxis - course, mechanism and treatment. JAMA 1974; 272; 1431-6.

25 Moss J, Fahmy NR, Sunder N, Beaven MA. Hormonal and hemodynamic profile of an anaphylactic reaction in man. Circulation 1981; 63: 210-3.

26 Bristow MR, Minobe WA, Billingham ME et al. Anthracycline-associated cardiac and renal damage in rabbits: evidence for mediation by vasoactive substances. Lab Invest 1981; 45: 157-68.

27 Velaquez $J$, Gold $M I$. Anaphylactic reaction to cephalothin during anaesthesia. Anesthesiology 1975; 43: 476-8.

28 Barnett AS, Hirshman CA. Anaphylactic reaction to cephapirin during spinal anaesthesia, Anesth Analg 1979; 58: 337-8.

29 Watkins J, Thornton JA, Clarke RSJ. Adverse reactions to i.v. agents. Br J Anesth 1979; $51: 469$.

30 Clarke RSJ. Adverse effects of intravenously administered drugs used in anaesthetic practice. Drugs 1981; 22: 26-41.

31 Lorenz W, Doenicke A, Schonig B, Neugebauer E. The role of histamine in adverse reactions to intravenous agents. In: Adverse Reactions of Anaesthetic Drugs. Ed: Thomton JA. Amsterdam: Elsevier/ North-Holland Biomedical Press 1981; pp. 169238.

32 Laxenaire MC, Moneret-Vautrin DA, Watkins J. Diagnosis of the causes of anaphylactoid anaesthetic reactions. Anaesthesia 1983; 38: 147-8.

33 Fisher $M$. Intradermal testing after anaphylactoid reaction to anaesthetic drugs: practical aspects of performance and interpretation. Anaesth Intensive Care 1984; 12: 115-20. 
34 Kniker WT, Hales SW, Lee LK. Diagnostic methods to demonstrate IgE antibodies: skin testing techniques. Bull NY Acad Med 1981; 57: 524-48.

35 Coca $A F$, Grove EE. Studies in hypersensitiveness. XIII. A study of atopic reagents. J Immunol 1925; 10: 335-64.

36 May $C D$, Lyman $M$, Alberto R, Cheng J. Procedures for immunochemical study of histamine release from leukocytes with small volume of blood. $\mathbf{J}$ Allerg 1970; 46: 12-20.

37 Guldager H, Sondergaard I, Jensen FM, Cold G. Basophil histamine release in asthma patients after in vitro provocation with althesin and etomidate. Acta Anaesthesiol Scand 1985; 29: 352-3.

38 Girsh LS, Perelmutter LL. The diagnosis of drug allergies utilizing in vitro mast cell test and IgE inhibition test. Immunol Allergy Pract 1978; 3: 158-68.

39 Gleich GH, Yunginger JW. The radioallergosorbent test: a method to measure IgE antibodies, IgG blocking antibodies, and the potency of allergy extracts. Bull NY Acad Med 1981; 57: 559-67.

40 Dueck $R, O^{\prime}$ Connor $R D$. Thiopental: false-positive RAST in patients with elevated serum IgE. Anesthesiology 1984; 61: 337-8.

41 Levy $J H$, Rockoff $M A$. Anaphylaxis to meperidine. Anesth Analg 1982; 61: 301-3.

42 Westacott $P$, Ramachandran $P R$, Jancelewicz $Z$. Anaphylactic reaction to thiopentone: A case report. Can Anaesth Soc J 1984; 31: 434-8.

43 Hirshman CA, Peters J, Cartwright-Lee 1. Leukocyte histamine release to thiopental. Anesthesiology 1982; 56: 64-7.

44 Evans $J M$, Keogh JAM. Adverse reactions to intravenous anaesthetic induction agents. Br Med J 1977; 2: 735-6.

45 Driggs $R L, O$ Day RA. Acute allergic reaction associated with methohexital anaesthesia: report of six cases. J Oral Surg 1972; 30: 906-9.

46 Watkins J, Clarke $S J$, Report of a symposium: adverse responses to intravenous agents. Br J Anaesth 1978; 50: 1159-64.

47 Davis J. Thiopentone anaphylaxis. Br J Anaesth 1971; 43: 1191-3.

48 Doenicke A. Propanidid. In: Proceedings of the IV European Congress of Anaesthesiology. Amsterdam: Excerpta Medica. pp. 107-13.

49 Christman D. Immune reaction to propanidid. Anaesthesia 1984; 39: 470-3.

50 Huttel MS, Schou Olesen A, Stoffersen E. Comple- ment-mediated reactions to diazepam with cremophor as solvent (Stesolid MR). Br J Anaesth 1980; 52: 77-9.

51 Beamish D, Brown DT. Adverse responses to IV anaesthetics. Br J Anaesth 1981; 53: 55-7.

52 Mathieu A, Goudsouzian N, Snider MT. Reaction to ketamine: anaphylactoid or anaphylactic? Br J Anaesth $1975 ; 47$ : 624-7.

53 Watkins $J$, Salo $M$. Incidence of immediate adverse response to intravenous anaesthetic drugs. In: Trauma, Stress and Immunity in Anaesthesia and Surgery. Butterworth \& Co. Ltd., 1982; 272.

54 Brown DT, Beamish D, Wildsmith JAW. Allergic reaction to an amide local anesthetic. $B r \mathrm{~J}$ Anaesth 1981; 53: 435-7.

55 Schwartz $H J$, Sher $T H$. Bisulfite sensitivity manifesting as allergy to local dental anaesthesia. J Allergy Clin Immunol 1985; 75: 525-7.

56 Writer WDR, Davies JM, Strunin L. Trial by media: the bupivacaine story. Can Anaesth Soc J 1984; 31 : $1-4$.

57 Lim M, Churchill-Davidson HC. Adverse effects of neuromuscular blocking drugs. In: Thornton JW, ed. Adverse Reactions to Anaesthetic Drugs. Oxford: Elsevier, 1981; 65-136.

58 La Forest M, More D. Fisher MMcD. Predisposing factors in anaphylactoid reactions in an Australian population: the role of allergy, atopy and previous anaesthesia. Anaesth Intensive Care 1980; 8: 454-9.

59 Fisher $M M c D$, Munro I. Life-threatening anaphylactoid reactions to muscle relaxants. Anesth Analg 1983; 62: 559-64.

60 Ravindram RS, Kleem JE. Anaphylaxis to succinylcholine in a patient allergic to penicillin. Anesth Analg 1980; 59: 944-5.

61 Yeung $M L, N g M Y, K o o$ AWL. Severe bronchospasm in an asthmatic patient following alcuronium and d-tubocurarine. Anaesth Intensive Care 1979; 7 : 62-4.

62 Assesm ESK, Frost PG, Levis RD. Anaphylactoidlike reaction to suxamethonium. Anaesthesia 1981; 36: 405-10.

63 Morrow JG. Allergy to succinylcholine. Anesth Analg 1981; 60: 456.

64 Miller $R$, Tausk HC. Anaphylactoid reaction to vancomycin during anaesthesia: a case report. Anesth Analg 1977; 56: 870-2.

65 Symons NLP, Hobbes AFT, Leaver HK. Anaphylactoid reactions to vancomycin during anaesthesia: 
two clinical reports. Can Anaesth Soc J 1985; 32: 178-81.

66 Newfield P. Poizer MF. Hazards of rapid administration of vancomycin. Ann Int Med 1979; 91: 581.

67 Chymopapain for herniated lumbar discs. Medical Letter 1983; 25: 41-2.

68 Bruno LA, Smith DS, Bloom MJ et al. Sudden hypotension with a test dose of chymopapain. Anesth Analg 1984, 63: 533-5.

69 Shehadi WH, Toniolo G. Adverse reactions to contrast media. Radiology 1980; 136: 299-302.

70 Ansell G, Tweedie MCK, West CR, Evans $P$, Couch $L$. The current status of reactions to intravascular contrast media. Invest Radiol 1980; 15: 532-9.

71 Ansell $G$. Adverse reaction to contrast agents. Scope of problem. Invest Radiol 1970; 5: 374-91.

72 Goldberg $M$. Systemic reactions to intravascular contrast media. A guide for the anesthesiologist. Anesthesiology 1984; 60: 46-56.

73 Isbister JP, Fisher MMCD. Adverse effects of plasma volume expanders. Anesth Intensive Care 1980; 8: 145-51.

74 Colman WR. Paradoxical hypotension after volume expansion with plasma protein fraction. N Engl J Med 1978; 299: 97.

75 Hilgard $P$. Immunological reactions to blood and blood products. Br J Anesth 1979; 51: 45-9.

76 Knape JTA, Schuller JL, DeHaan P, DeJong AP, Bovill JG. An anaphylactic reaction to protamine in a patient allergic to fish. Anesthesiology 1981; 55: 324-5.

77 Hellema HWJ, Rumke P. Sperm autoantibodies as a consequence of vasectomy. I. Within 1 year postoperation. Clin Exp Immunol 1978; 31: 18-29.

78 Doolan L, McKenzie I, Krafchek J, Parsons B, Buxton $B$. Protamine sulphate hypersensitivity. Anesth Intensive Care 1981; 9: 147-9. 